\title{
DAMPAK PROGRAM PENINGKATANPRODUKSI BERAS NASIONAL(P2BN)TERHADAP PENDAPATAN PETANI DI KABUPATEN SIDENRENG RAPPANG
}

\author{
IMPACT OF NATIONAL RICE PRODUCTION PROGRAM (P2BN) ON FARMERS 'INCOME IN \\ SIDENRENG DISTRICT, RAPPANG
}

\begin{abstract}
Abd.Harake, Nurhapsa
Faculty of Agriculture, Animal Husbandry and Fisheries Muhammadiyah

University Parepare

e-mail: hapsa_faktan@yahoo.co.id
\end{abstract}

\begin{abstract}
ABSTRAK
Tujuan penelitian ini adalah menganalisa dampak program Peningkatan Produksi Beras Nasional (P2BN) terhadap pendapatan petani di Kelurahan Pangkajene, Kecamatan Maritengngae, Kabupaten Sidrap. Jumlah sampel diambil sebanyak 30 responden yang menjadi peserta program P2BN dan 30 responden petani yang tidak ikut program P2BN. Prosedur dan pengumpulan data primer dan data sekunder yang bersifat kuantitatif maupun kualitatif yang berkaitan dengan penelitian ini. Data primer didapat melalui pengamatan langsung dan wawancara langsung maupun dengan menggunakan kuisioner. Hasil penelitian menunjukkan bahwa terdapat perbedaan pendapatan antara petani peserta program P2BN dengan petani bukan peserta program P2BN. Pendapatan petani peserta program P2BN lebih tinggi dibandingkan pendapatan petani bukan peserta program P2BN. Dengan mengikuti program $\mathrm{P} 2 \mathrm{BN}$, petani dapat menurunkan biaya riil usahataninya.
\end{abstract}

\section{Kata Kunci : P2BN, pendapatan, produksi, petani, padi}

\begin{abstract}
The purpose of this study was to analyze the impact of the National Rice Production Improvement program (P2BN) on the income of farmers in Pangkajene Village, Maritengngae District, Sidrap Regency. The number of samples taken were 30 respondents who were participants in the $P 2 B N$ program and 30 respondents of farmers who did not participate in the P2BN program. Procedure and collection of primary and secondary data that are both quantitative and qualitative in nature related to this study. Primary data is obtained through direct observation and direct interviews or by using questionnaires. The results showed that there were differences in income between farmers participating in the $P 2 B N$ program and farmers not participants in the $P 2 B N$ program. The income of farmers participating in the $P 2 B N$ program is higher than the income of farmers who are not participants in the $P 2 B N$ program. By participating in the $P 2 B N$ program, farmers can reduce the real costs of their farming.
\end{abstract}

Keyword : P2Bn, Income, production, thefarmer, paddy 


\section{PENDAHULUAN}

Sektor pertanian merupakan salah sektor yang sangat berperan dalam perekonmian Indonesia. Hal ini ditunjukkan dengan sumbangan sektor pertanian terhadap PDB yaitu menempati urutan kedua setelah sektor industri pengolahan. Sektor pertanian juga merupakan sumber uatama dalam menopang ketahanan pangan nasional. Peran lain sektor pertanian adalah menyediakan lapangan kerja, penyedia bahan baku bagi industri khususnya industri makanan dan minuman (Nurhapsa, 2015).

Subsektor tanaman pangan merupakan salah satu subsektor dalam sektor pertanian yang memiliki peran yang sangat besar dalam perkeonomian Indonesia. Sebagian besar penduduk Indonesia bekerja di sub sektor tanaman pangan. Dengan dukungan kebijakan pemerintah yang mengutamakan pembangunan pertanian yang didukung dengan kebijakan ekonomi makro untuk meningkatkan peran sektor pertanianmelalui terobosan teknologi baru yaitu revolusi hijau. Terobosan teknologi baru ini berupa budidaya padi sawah dan kebijakan intensifikasi pertanian (BIMAS). Penerapan teknologi tersebut berdampak terhadap peningkatan produksi padi dan Indonesia pernah menjadi swasembada beras. Namun disisi lain, teknologi tersebut menimbulkan kerusakan lingkungan disertai dengan resistensi hama terhadap pestisida yang disebabkan konsumsi pestisida dan pupuk kimia yang meningkat.

.Pada tahun 1994 pasca swasembada beras, impor beras Indonesia kembali meningkat dan mencapai puncaknya pada tahun 1999 dengan volume impor sekitar
4.7 juta ton. Pada tahun 2004 penurunan impor beras sekitar 83.4 persen dibanding tahun 2003. Hal tersebut disebabkan pemerintah melakukan perlindungan terhadap petani dengan menetapkan kebijakan impor beras. berdasarkan keputusan Menteri Perindustrian dan Perdagangan No.9/MPP/Kep/1/2004. Selain itu, upaya menurunkan impor beras dilakukan dengan meningkatkan produksi dan produktivitas padi nasional. Rata-rata laju pertumbuhan luas lahan dari tahun 1994 sampai tahun 2007 sebesar 0,94 persen per tahun dan rata-rata laju pertumbuhan produksi padi sebesar 1,48 persen per tahun. (Lubis, 2005).

Untuk meningkatkan pendapatan dan kesejahteraan petani, maka diperlukan perbaikan dan penyempurnaan programprogram pembangunan pertanian seperti program intensifikasi padi baik dari budidaya maupun aspek kelembagaannya. - Selain program intensifikasi padi, program $\mathrm{P} 2 \mathrm{BN}$ juga merupakan salah satu program yang bertujuan untuk meningkatkan pendapatan dan kesejahteraan petani. Oleh karena itu, maka penelitian ini dilakukan untuk mengetahui dampak Program Peningkatan Produksi Beras Nasional (P2BN) Terhadap Pendapatan Petani di Kab. Sidrap.

\section{MATERI DAN METODE PENELITIAN}

Penelitian dilaksanakan di Kelurahan Pangkajene, Kecamatan Maritenggae, Kabupaten Sidrap, Propinsi Sulawesi Selatan. Metode yang digunakan dalam penelitian ini adalah metode survey dan observasi. Pengumpulan data dilakukan dengan cara pengamatan langsung dan wawancara dengan 
menggunakan kuesioner sebanyak 30 responden yang menjadi peserta program P2BN dan 30 responden yang tidak menjadi peserta program P2BN. Jenis data yang dikumpulkan adalah data primer dan data sekunder baik kuantitatif maupun kualitatif yang diperoleh dari Badan Pusat Statistik (2004). Data yang diperoleh dianalisis dengan menggunakan uji-t untuk membandingkan rata-rata dua kelompok yang tidak saling berpasangan. Hasil pengujian variabel penelitian menggunakan program SPPS.

\section{HASIL DAN PEMBAHASAN}

\section{Persepsi Petani terhadap Program Peningkatan Produksi Beras Nasional (P2BN)}

Persepsi merupakan tindakan menyusun, mengenali dan menafsirkan suatu informasi untuk memberikan uraian atau gambaran tentang suatu lingkungan. Persepsi mempenhauhi setiap orang dalam bertindak. Persepsi seseorang tergantung pada seberapa jauh suatu objek arti dan manfaat terhadap seseorang dan persepsi juga melibatkan derajat kesadaran, suatu arti atas penghargaan terhadap objek tersebut .

Program P2BN dilaksanakan di Kelurahan Pangkajene, Kecamatan Maritenggae, Kabupaten Sidrap sejak tahun 2007. Program ini bertujuan untuk (1) meningkatkan produksi padi, (2) membuka kesempatan kerja dan berusaha, (3) memperbaiki pendapatan dan kesejahteraan petani dan (4) memantapkan koordinasi, integrasi para pemangku kepentingan dari pusat sampai daerah.

Hasil penelitian yang dilakukan menunjukkan dengan adanya program P2BN produksi padi Kecamatan
Maritenggae, Kabupaten Sidrap terjadi peningkatan, sebelum adanya program P2BN rata-rata hasil produksi padi per hektar rata-rata sebesar $4.483 \mathrm{~kg}$ per hektar dan setelah program P2BN hasil petani padi rata-rata hasil produksi padi per hektar sebesar $5.500 \mathrm{~kg}$ per hektar.

Program P2BN yang direncanakan oleh pemerintah dapat membantu petani. Petani yang berada di Kelurahan Pangkajene, Kecamatan Maritenggae, Kabupaten Sidrap, telah melaksanakan program P2BN sejak tahun 2007. Penyaluran bantuan benih besertifikat ini antara Dinas Pertanian Sidrap dengan ketua kelompok tani mengadakan surat perjanjian bahwa pada tahun 2007 serah terima benih yang akan disalurkan kepada petani. Pihak kesatu sebagai Dinas Pertanian dan pihak kedua sebagai ketua kelompok tani. Penyerahan dan penyaluran benih ini, diawali dengan pihak kesatu menyerahkan kepada pihak kedua bantuan benih dalam keadaan baik, selanjutnya seluruh petani di Kelurahan Pangkajene telah mengikuti program P2BN dan terdiri dari tiga kelompok tani. Para petani yang ada mendapatkan informasi tentang adanya program P2BN dari masing-masing ketua kelompok tani, dimana masing-masing ketua kelompok tani sebelumnya telah mendapatkan penyuluhan dari Dinas Pertanian setempat.

Petani yang melaksanakan program P2BN yang disarankan oleh pemerintah beralasan hanya mengikuti saran dari ketua kelompok tani masing-masing. Selama itu, petani berpendapat bahwa dengan melaksanakan program P2BN dapat mengurangi biaya sarana produksi. Hal ini dikarenakan benih yang digunakan oleh petani program $\mathrm{P} 2 \mathrm{BN}$ didapat secara gratis dari pemerintah, sehingga biaya untuk membeli benih dapat dialokasikan 
ke sarana produksi yang lain. Benih yang digunakan oleh petani program $\mathrm{P} 2 \mathrm{BN}$ merupakan benih bersertifikat label putih. Varietas yang ditanam petani adalah varietas unggulan di Kelurahan Pangkajene, Kabupaten Sidrap.

Syarat yang ditetapkan oleh (Dinas Pertanian. 2007), bagi petani yang mendapat program P2BN yaitu petani yang mempunyai luas lahan lima hektar dianggap petani yang sudah maju. Adanya syarat yang ditetapkan oleh Dinas Pertanian dianggap petani tidak memberatkan dan sudah cukup bijaksana, karena dapat membantu petani yang tergolong kurang maju.

Mekanisme pembagian bantuan benih untuk setiap petani dilakukan oleh ketua kelompok tani masing-masing. Benih yang diberikan oleh pemerintah berasal dari produsen benih Syang Hyang Seri, oleh masing-masing ketua kelompok tani. Kedua kelompok tani membagikan kepada setiap anggota petani yang melaksanakan program P2BN sebesar 20 $\mathrm{kg}$ per hektar untuk masing-masing petani. Dalam proses pengambilan benih tidak ada hambatan atau kesulitan yang ditemui. Dalam pengambilan benih sudah tepat waktu yaitu pada saat mulai musim tanam padi tiba.

Program P2BN yang telah dilaksanakan pada tahun 2007

di Kelurahan Pangkajene dianggap petani sudah cukup berhasil, ditandai dengan benih yang diberikan oleh pemerintah dapat meningkatkan hasil produksi petani padi. Produksi padi sebelum adanya program $\mathrm{P} 2 \mathrm{BN}$ rata-rata sebesar $4.483 \mathrm{~kg}$ per hektar, sedangkan produksi padi setelah adanya program P2BN terjadi peningkatan hasil menjadi $5.500 \mathrm{~kg}$ per hektar, hal ini menunjukkan bahwa program $\mathrm{P} 2 \mathrm{BN}$ berperan positif terhadap peningkatan kesejahteraan petani di lokasi penelitian.

Dengan adanya program $\mathrm{P} 2 \mathrm{BN}$ dapat mengurangi biaya sarana produksi. Hal ini dikarenakan benih yang digunakan oleh petani program $\mathrm{P} 2 \mathrm{BN}$ diterima secara gratis dari pemerintah, sehingga biaya untuk membeli benih dapat dialokasikan ke sarana produksi yang lain. Program P2BN ini, selain menyediakan benih berkualitas juga dapat membantu petani yang tergolong kurang maju. Dengan adanya program $\mathrm{P} 2 \mathrm{BN}$, petani yang telah bergabung dalam kelompok tani sering mendapat informasi terbaru mengenai perkembangan teknologi pertanian dari tenaga penyuluh pertanian (PPL) setempat. Dengan demikian satu inovasi teknologi, yaitu penggunaan benih bersertifikat, telah dilaksanakan tanpa ada hambatan.

Keberhasilan program $\mathrm{P} 2 \mathrm{BN}$ pada tahun 2007 diharapkan petani padi di daerah penelitian dapat melaksanakan kembali pada tahun 2013 di setiap musim tanam. Selain membantu dalam pengurangan biaya saprodi, program P2BN juga membantu petani dalam penyediaan benih berkualitas yang dapat meningkatkan produksi padi, sehinga pendapatan petani meningkat. Harapan petani di daerah penelitian, agar dari pihak Dinas Pertanian agar benih besertifikat ini terus ditingkatkan dalam hal mutu yang lebih berkualitas misalnya varietas Ciliwung bersertifikat berlabel putih. Program P2BN ini menurut petani di daerah penelitian sudah cukup membantu para petani. Program P2BN ini menurut petani di daerah penelitian sudah cukup membantu para petani, akan tetapi masih banyak masalah yang harus diperhatikan oleh pemerintah misalnya harga pupuk, 
obat-obatan pada masa waktu tanam melambung tinggi.

Struktur usahatani padi mencakup struktur biaya saprodi, biaya tenaga kerja , hasil produksi, harga jual dan pendapatan dari penjualan yang diperoleh petani untuk satu musim tanam. Rata-rata penggunaan biaya tenaga kerja dan biaya saprodi pada usahatani padi dengan program $\mathrm{P} 2 \mathrm{BN}$ berbeda dengan non program $\mathrm{P} 2 \mathrm{BN}$ (Tabel 1). Adapun biaya tenaga kerja yang dikeluarkan adalah penanaman, sewa traktor, dan panen, Untuk lebih jelasnya rata-rata penggunaan biaya tenaga kerja petani program $\mathrm{P} 2 \mathrm{BN}$ dengan petani non program $\mathrm{P} 2 \mathrm{BN}$, sedangkan biaya saprodi atau sarana produksi adalah bibit/benih, pupuk, pestisida, fungisida dan herbisida.

Tabel 1. Dampak Kebijakan Program P2BN terhadap Pendapatan Petani Padi.

\begin{tabular}{lrrl}
\hline \multicolumn{1}{c}{ Atribut } & Non Program & \multicolumn{1}{c}{ Program } & Dampak \\
& \multicolumn{1}{c}{ P2BN } & \multicolumn{1}{c}{ P2BN } & \\
\hline Pendapatan & 15.300 .000 & 18.300 .000 & Meningkat \\
Biaya Tenaga Kerja & 2.790 .000 & 2.660 .000 & Menurun \\
Biaya Saprodi & 2.400 .000 & 2.150 .000 & Menurun \\
Hasil Produksi & 4.483 & 5.000 & Meningkat \\
Harga Jual & 3.450 & 3.700 & Meningkat
\end{tabular}

Sumber : Petani, Tahun 2013

Tingkat pendapatan petani program $\mathrm{P} 2 \mathrm{BN}$ dengan non program P2BN menunjukkan adanya perbedaan . Perbedaan yang dikarenakan pengeluaran untuk biaya tenaga kerja, biaya saprodi, produksi yang dihasilkan dan harga jual yang berbeda antara petani program $\mathrm{P} 2 \mathrm{BN}$ dengan non program P2BN. Berdasarkan dari hasil analisis dan perhitungan yang dilakukan, menunjukkan bahwa produksi dan pendapatan petani peserta program P2BN meningkat dibandingkan dengan produksi dan pendapatan petani yang tidak mengikuti program P2BN. Selain itu, peningkatan produksi dan pendapatan petani juga dipengaruhi oleh kualitas lahan, varietas benih, pupuk dan cuaca

Pendapatan petani program $\mathrm{P} 2 \mathrm{BN}$ menunjukkan pendapatan yang tinggi, karena hasil produksi meningkat sebesar 83,0 persen. Perbedaan ini di karenakan oleh tingkat produksi yang berbeda, sementara harga jual adalah $3.450 / \mathrm{kg}$. Besarnya penerimaan yang diterima oleh petani sangat tergantung dengan hasil produksi yang dihasilkan. Tinggi rendahnya pendapatan dipengaruhi oleh tinggi rendahnya produksi..

\section{Dampak Kebijakan Program P2BNterhadap Pendapatan Petani .}

Dampak kebijakan program P2BN terhadap pendapatan petani padi Ciliwung di Kelurahan Pangkajene, Kecamatan Maritenggae, Kabupaten Sidrap, Provinsi Sulawesi Selatan dilakukan, dengan membandingkan petani padi program $\mathrm{P} 2 \mathrm{BN}$ dan non program $\mathrm{P} 2 \mathrm{BN}$.

Berdasarkan Tabel 1 menunjukkan pendapatan petani padi meningkat setelah mendapatkan program $\mathrm{P} 2 \mathrm{BN}$ dengan ratarata $\mathrm{Rp}$ 15.300.000 per hektar menjadi $\mathrm{Rp}$ 18.300.000 per hektar setelah mengikuti program $\mathrm{P} 2 \mathrm{BN}$.

Pembayaran tenaga kerja dilokasi penelitian yang berbeda, dengan demikian, 
tiap sampel penelitian memiliki biaya tenaga kerja yang berbeda. Terdapat penurunan biaya tenaga kerja petani padi setelah mendapatkan program $\mathrm{P} 2 \mathrm{BN}$ dengan rata-rata $\mathrm{Rp} 2.790 .000$ per hektar menjadi Rp 2.660.000 per hektar setelah mengikuti program P2BN.. Pada petani non program $\mathrm{P} 2 \mathrm{BN}$, upah tenaga kerja yang paling rendah Rp. 2.700.000 dan yang paling tinggi Rp.2.860.000 sedangkan petani program $\mathrm{P} 2 \mathrm{BN}$, upah yang paling rendah Rp. 2.500.000 dan yang paling tinggi Rp. 2.720.000,

Table 1 menunjukkan penggunaan biaya saprodi menurun setelah mengikuti program $\mathrm{P} 2 \mathrm{BN}$ dengan rata-rata $\mathrm{Rp}$ 2.400.000 per hektar menjadi Rp 2.150.000 per hektar setelah mengikuti program P2BN. Pada petani non program $\mathrm{P} 2 \mathrm{BN}$, biaya saprodi yang paling rendah Rp. 2.308.000 dan yang paling tinggi Rp.2.448.000 sedangkan petani program P2BN, biaya saprodi yang paling rendah Rp. 2.228.000 dan yang paling tinggi Rp. 2.308.000 Petani sudah menggunakan bibit padi varietas unggul yang dianjurkan oleh pemerintah, pola jarak tanam padi sudah teratur yaitu pola tanam jajar legowo 4 dan 6 baris tanaman padi yang diselingi dengan baris yang dikosongkan.. Jarak tanam legowo 4 dan 6 masingmasing $15 \mathrm{~cm} \times 20 \mathrm{~cm} \times 40 \mathrm{~cm}$ dan $20 \mathrm{~cm}$ x $25 \mathrm{~cm}$ x $50 \mathrm{~cm}$, pupuk sesuai dosis, dilakukan penyiangan, dan pemupukan lanjutan secara berkala 7-8 kali per musim. Bibit yang digunakan merupakan bibit yang dianjurkan oleh pemerintah yaitu varietas Ciliwung bersertifikat berlabel putih sehingga memiliki kualitas yang seragam. Produksi dan pendapatan petani di lokasi penelitian meningkat setelah mengikuti program $\mathrm{P} 2 \mathrm{BN}$ karena petani menggunakan bibit unggul. Program
P2BN mampu meningkatkan produksi petani rata-rata dari $4.483 \mathrm{~kg}$ per hektar menjadi $5.000 \mathrm{~kg}$ per hektar. Peningkatan produksi disebabkan oleh penggunaan varietas benih padi yang berkualitas yaitu varietas ciliwung dan penggunaan jarak tanam yang sesuai dengan anjuran.

$\begin{array}{llr}\text { Petani } & \text { padi sebagian } \\ \text { besar masih } & \text { menjual kepada }\end{array}$ pedagangpengumpul atau tengkulak tanpa dilakukan pengolahan terlebih dahulu. Nilai tambah yang seharusnya dinikmati oleh petani hilang dan menjadi keuntungan para pedagang pengumpul, karena panjangnya rantai pemasaran padi. Cara untuk memperpendek rantai pemasaran dengan forum pemasaran bersama padi sehingga petani bisa langsung menjual padi pada tengkulak. Peningkatan harga padi pada non program $\mathrm{P} 2 \mathrm{BN}$ harga rata-rata $\mathrm{Rp} 3.450$ per $\mathrm{kg}$, sedangkan petani program $\mathrm{P} 2 \mathrm{BN}$ harga rata-rata $\mathrm{Rp}$ 3.700 per $\mathrm{kg}$, naiknya harga tersebut karena kualitas padi yang dihasilkan lebih baik dari pada sebelum program. Dampak peningkatan harga padi juga dirasakan petani padi setelah adanyaprogram $\mathrm{P} 2 \mathrm{BN}$.

\section{Harga Jual}

Harga yang diterima oleh petani yang mendapat program $\mathrm{P} 2 \mathrm{BN}$ rata-rata sebesar Rp 3.700 per $\mathrm{kg}$ dan harga petani yaprogram $\mathrm{P} 2 \mathrm{BN}$ rata-rata sebesar $\mathrm{Rp}$ 3.450 per $\mathrm{kg}$. Selisih perbedaan harga yang diterima oleh petani yang ikut program $\mathrm{P} 2 \mathrm{BN}$ dengan petani yang tidak ikut program P2bn adalah Rp Rp 163 per ha. Dengan demikian dapat disimpulkan bahwa di lokasi ini keberadaan P2BN berdampak positif dalam menolong harga gabah di tingkat petani. 
Pendapatan antara petani yang mendapat program P2BN, Dumairy 1999. Dengan non program P2BN. Perbandingan antara petani yang mendapat program $\mathrm{P} 2 \mathrm{BN}$ dengan yang tidak mendapat program P2BN. Pendapatan yang diterima oleh petani yang mendapat pro rata-rata sebesar Rp 18.300.000 per ha dan pendapatan petani yang non program P2BN rata-rata sebesar $\mathrm{Rp} 15.300 .000$ per ha. Terdapat perbedaan pendapatan yang diterima antara petani yang mendapat porgram $\mathrm{P} 2 \mathrm{BN}$ dengan non program P2BN sebesar Rp 3.000.000 per ha. Dengan demikian dapat disimpulkan bahwa di lokasi ini keberadaan P2BN berdampak positif dalam meningkatkan pendapatan petani.

Secara deskriptif ini menunjukkan bahwa petani yang mendapatkan program P2BN lebih baik dalam melaksanakan aktivitas usahataninya. Dalam hal perbedaan pendapatan antara petani yang mendapat program $\mathrm{P} 2 \mathrm{BN}$ dan yang tidak mendapat program $\mathrm{P} 2 \mathrm{BN}$, faktor lain selain program P2BN memang dianggap caterisparibus. Berdasarkan hal ini tingginya pendapatan petani yang mendapatkan $\mathrm{P} 2 \mathrm{BN}$ selain

a. Perbandingan dengan program $P 2 B N$ dengan non program $P 2 B N$ dari pendapatan

Berdasarkan hasil pengujian, diketahui nilai sig. Di tabel levene's test for equality of variances .114> 0,05. Hasil ini menunjukkan bahwa variasi kelompok yang sama, sehingga untuk analisis selanjutnya digunakan hasil pengujian dikolom equal variances not assumed. Dari kolom tersebut didapati nilai t-hitung $-13.542>$ t-tabel 2.024. Nilai negatif dalam hal ini dianggap mutlak. karena P2BN-nya faktor lain seperti produktivitas yang tinggi dan biaya yang lebih rendah. Namun dalam penelitian ini diasumsikan bahwa perbedaan pendapatan tersebut disebabkan terutama karena perbedaan benih yang digunakan dan harga yang diterima petani antara petani yang mendapatkan program $\mathrm{P} 2 \mathrm{BN}$ dengan non program $\mathrm{P} 2 \mathrm{BN}$,yang dalam hal ini program P2BN berperan langsung. Analisis perbandingan dilakukan pada proses biaya tenaga kerja, biaya saprodi, hasil produksi , harga jual petani padi dan pendapatan petani.

\section{Hasil Analisis Uji t Sampel Independen}

Variabel-variabel yang diuji adalah biaya tenaga kerja, biaya saprodi, hasil produksi, harga jual, serta pendapatan. Dari hasil pengujian dengan uji t sampel independen, didapati beberapa variabel yang hasilnya tidak sesuai dengan hipotesis sebelumnya. Dari hasil pengujian diketahui semua variabel signifikan, biaya tenaga kerja, Biaya saprodi, produksi, harga jual dan pendapatan.

Dari hasil pengujian ini diketahui terdapat perbedaan rata-rata pendapatan petani antara petani non program $\mathrm{P} 2 \mathrm{BN}$ dengan petani program $\mathrm{P} 2 \mathrm{BN}$. Untuk mengetahu rata-rata pendapatan manakah yang meningkat dilakukan dengan melihat nilai mean groupstatistics. Pendapatan pada penelitian ini di hitung satuan rupiah/ hektar/musim tanam. Nilai mean pendapatan petani program P2BN 18.300 $<$ pendapatan non program P2BN (Tabel 2). Dari antara keduanya terdapat selisih sebesar Rp. 3.000.000. hasil ini sesuai dengan hipotesis sebelumnya yang 
menyatakan pendapatan petani program P2BN lebih besar dari pada petani non program $\mathrm{P} 2 \mathrm{BN}$, sehingga hipotesis yang dii ajukan di terima.

Tabel 2. Rekapitulasi Hasil Pengujian Variabel Penelitian

\begin{tabular}{|c|c|c|c|c|c|}
\hline \multirow[t]{2}{*}{ No } & \multirow[t]{2}{*}{ Uraian } & \multicolumn{2}{|c|}{$\begin{array}{c}\text { Mean } \\
\text { (Group Statistic) }\end{array}$} & \multirow[t]{2}{*}{ Hipotesis } & \multirow[t]{2}{*}{ Hasil uji } \\
\hline & & $\pi_{1}$ & $\pi_{2}$ & & \\
\hline 1 & Biaya Tenaga kerja & 2.790 .000 & 2.660 .000 & $\pi_{1}<\pi_{2}$ & $\pi_{1}>\pi_{2}$ \\
\hline 2 & Biaya Saprodi & 2.400 .000 & 2.150 .000 & $\pi_{1}<\pi_{2}$ & $\pi_{1}<\pi_{2}$ \\
\hline 3 & Hasil Produksi & 4483.33 & 5000.00 & $\pi_{1}>\pi_{2}$ & $\pi_{1}<\pi_{2}$ \\
\hline 4 & Harga Jual & 3450.00 & 3700.00 & $\pi_{1}>\pi_{2}$ & $\pi_{1}<\pi_{2}$ \\
\hline 5 & Pendapatan & 15.300 .000 & 18.300 .000 & $\pi_{1}<\pi_{2}$ & $\pi_{1}<\pi_{2}$ \\
\hline
\end{tabular}

Sumber: Data SPPS yang telah diolah.

Tabel 3. Hasil Uji t Sampel Independen Variabel Penelitian

\begin{tabular}{llccccc}
\hline \multirow{2}{*}{ No Uraian } & \multicolumn{2}{c}{ Levene's Test } & \multicolumn{3}{c}{ T-test } \\
\cline { 3 - 7 } & & $\mathrm{F}$ & $\mathrm{Sig}$ & $\mathrm{t}$-tab & t-hit & Df \\
\hline 1 & Pendapatan & 2.569 & .114 & 2.024 & -13.542 & 58 \\
2 & Biaya Tenaga kerja & 11.465 & .001 & 2.024 & 6.398 & 58 \\
3 & Biaya Saprodi & 25.098 & .000 & 2.024 & 10.646 & 58 \\
4 & Hasil Produksi & .403 & .528 & 2.024 & -6.656 & 58 \\
5 & Harga Jual & .962 & .000 & 2.024 & -26.926 & 58 \\
\hline
\end{tabular}

Sumber: Data SPPS yang telah diolah.

\section{b. Perbandingan dengan program $P 2 B N$ dengan non program $P 2 B N$ dari segi biaya tenaga kerja}

Hasil ini menunjukkan bahwa variasi kelompok tidak sama, sehingga analisis selanjutnya, sehingga untuk analisi selanjutnya digunakan hasil pengujian dikolom equal variances not assumed. Dari kolom tersebut didapati nilai t-hitung 6,398 > t-tabel 2,024 (lihat tabel 3). Dari hasil analisis ini dapat disimpulkan terdapat perbedaan rata-rata biaya tenaga kerja antara petani program $\mathrm{P} 2 \mathrm{BN}$ dengan non program P2BN. Biaya tenaga kerja pada penelitian ini di hitung dalam satuan rupiah/ perhektar . Nilai mean biaya tenaga kerja petani program P2BN Rp. $2.660 .000>$ biaya tenaga kerja petani non program P2BN Rp. 2.790.000. dengan demikian rata-rata biaya tenaga kerja petani program $\mathrm{P} 2 \mathrm{BN}$ lebih rendah dari pada petani non program P2BN. Dari hasil ini terdapat selisih Rp. 130.000. Jika diperbandingkan antara biaya tenaga kerja petani program $\mathrm{P} 2 \mathrm{BN}$ dengan petani non program $\mathrm{P} 2 \mathrm{BN}$, ternyata biaya tenaga kerja petani program $\mathrm{P} 2 \mathrm{BN}$ lebih murah .

\section{c. Perbandingan dengan program P2BN dengan non program P2BN dari segi biaya saprodi}


Berdasarkan hasil pengujian ,diketahui nilai sig. Di tabel levene's test for equality of variances .000 < 0,05. Hasil ini menunjukkan bahwa variasi kelompok tidak sama, sehingga untuk analisis selanjutnya digunakan hasil pengujian dikolom equal variances not assumed. Dari kolom tersebut didapati nilai t-hitung10.646 < t-tabel 2.024 ( lihat tabel 3. Dari hasil analisis ini dapat disimpulkan terdapat perbedaan rata-rata biaya saprodi antara petani program $\mathrm{P} 2 \mathrm{BN}$ dengan petani non program P2BN. Untuk mengetahui rata-rata biaya saprodi manakah yang lebih besar dilakukan dengan melihat nilai mean di tabel group statistik. Biaya saprodi pada penelitian ini dihitung dalam satuan Rupiah/perhektar. Nilai mean biaya saprodi petani program $\mathrm{P} 2 \mathrm{BN}$ dengan petani non program $\mathrm{P} 2 \mathrm{BN}$ Rp. 2.400.000 > petani program $\mathrm{P} 2 \mathrm{BN}$ 2.150.000. Dengan demikian rata-rata biaya saprodi petani non program $\mathrm{P} 2 \mathrm{BN}$ Lebih tinggi dari pada petani program P2BN. Hasil ini sesuai dengan hipotesis sebelumnya, sehingga $\mathrm{H}_{\mathrm{i}}$ diterima dan $\mathrm{H}_{0}$ ditolak.

\section{d. Perbandingan dengan program $P 2 B N$ dengan non program $P 2 B N$ dari segi hasil produksi}

Berdasarkan hasil pengujian, diketahui nilai sig. Di tabel levene's test for equality of variances .528>0,05. Hasil ini menunjukkan bahwa variasi kelompok ada kesamaan, sehingga untuk analisis selanjutnya digunakan hasil pengujian dikolom equal variances not assumed. Dari kolom tersebut didapati nilai t-hitung $-6.656>$ t-tabel 2.024 ( lihat tabel 3). Nilai negatif dalam hal ini dianggap mutlak. Dari hasil analisis ini dapat disimpulkan terdapat perbedaan rata-rata produksi antara petani program $\mathrm{P} 2 \mathrm{BN}$ dengan petani non program P2BN. Untuk mengetahui rata-rata produksi manakah yang lebih besar dilakukan dengan melihat nilai mean di tabel group statistics. Produksi pada penelitian ini dihitung dalam satuan kilogram/hektar. Nilai mean produksi petani program P2BN 5000 kilogram (5 ton) $>$ produksi petani non program $\mathrm{P} 2 \mathrm{BN}$ 4483,33 kilogram (4,5 ton). (lihat tabel 2 ).Disimpulkan, rata-rata produksi petani program $\mathrm{P} 2 \mathrm{BN}$ lebih tinggi dari pada petani non program $\mathrm{P} 2 \mathrm{BN}$.

\section{e. Perbandingan dengan program $P 2 B N$ dengan non program $P 2 B N$ dari segi harga jual}

Berdasarkan hasil pengujian, diketahui nilai sig. Di tabel levene's test for equality of variances .000 < 0,05. Hasil ini menunjukkan bahwa variasi kelompok tidak sama, sehingga untuk analisis selanjutnya digunakan hasil pengujian dikolom equal variances not assumed. Dari kolom tersebut didapati nilai t-hitung -26.926>t-tabel 2.024 ( lihat tabel 3). Nilai negatif dalam hal ini dianggap mutlak. Dari hasil analisis ini dapat disimpulkan terdapat perbedaan rata-rata produksi antara petani program $\mathrm{P} 2 \mathrm{BN}$ dengan petani non program $\mathrm{P} 2 \mathrm{BN}$. Untuk mengetahui rata-rata harga jual manakah yang lebih besar dilakukan dengan melihat nilai mean di tabel group statistics. Produksi pada penelitian ini dihitung dalam satuan Rupiah/kilogram . Nilai mean harga jual petani program P2BN Rp. 3.700/kg < harga jual petani non program P2BN Rp. 3.450/kg. Dengan demikian rata-rata biaya petani program 
P2BN lebih tinggi dari pada petani non program P2BN. Hasil ini sesuai dengan hipotesis sebelumnya.

\section{PENUTUP}

\section{Kesimpulan}

1. Program $\mathrm{P} 2 \mathrm{BN}$ berdampak positif terhadap peningkatan pendapatan petani secara signifikan dibandingkan non program P2BN. Pendapatan petani padi meningkat setelah mendapatkan program $\mathrm{P} 2 \mathrm{BN}$ dengan rata-rata $\mathrm{Rp}$ 15.300.000 per hektar menjadi Rp 18.300.000 per hektar atau 83,60 $\%$ setelah mengikuti program $\mathrm{P} 2 \mathrm{BN}$.

2. Dampak program $\mathrm{P} 2 \mathrm{BN}$ terhadap biaya tenaga kerja pada petani non program P2BN sebesar Rp 2.790.000/ha, lebih tinggi dari ratarata biaya tenaga kerja petani program $\mathrm{P} 2 \mathrm{BN}$ yang sebesar $\mathrm{Rp}$ 2.660.000/ha atau 95,34\%.

3. Dampak program P2BN terhadap biaya saprodi pada petani non program P2BN sebesar Rp 2.400.000/ha, lebih tinggi dari ratarata biaya saprodi petani program P2BN yang sebesar Rp 2.150.000/ha atau 89,58\%.

4. Dampak program P2BN terhadap hasil produksi pada petani non program P2BN sebesar Rp 4483/ha, lebih tinggi dari rata-rata hasil produksi petani program P2BN yang sebesar Rp 5000/ha atau $89,66 \%$.

5. Dampak program P2BN terhadap harga jual pada petani non program
P2BN sebesar Rp $3.450 / \mathrm{kg}$, lebih tinggi dari rata-rata Harga jual petani program $\mathrm{P} 2 \mathrm{BN}$ yang sebesar Rp 3.700/kg atau 93,24\%.

\section{Saran}

1. Berdasarkan hasil dari wawancara dengan petani, sebaiknya diperhatikan masalah pembagian benih bersertifikat yang mendapatkan hanya petani yang bergabung dalam kelompok tani tidak mendapatkan benih bersertifikat.

2. Program P2BN berdampak terhadap peningkatan produksi dan pendapatan petani padi sehingga disarankan agar program ini tetap berkelanjutan untuk daerah-daerah penghasil padi dan belum pernah memperoleh bantuan program P2BN.

3. Sebaiknya melakukan kajian tentang dampak program peningkatan produksi dan pendapatan petani jagung dan kedelai

\section{DAFTAR PUSTAKA}

Badan Pusat Statistik. 2004. Luas Panen, Produksi, dan Produktivitas Padi Sidrap. Sidrap.

Dinas Pertanian. 2007. Laporan Akhir Peningkatan Produksi Beras Nasional $\quad(P 2 B N) . \quad$ Direktorat Jenderal Tanaman Pangan. Jakarta.

Dumairy, 1999. Perekonomian Indonesia. Jakarta : Erlangga

Lubis, K. 2005. Efektifitas Penyaluran Kredit Ketahanan Pangan dan 
Analisis Pendapatan Petani Pengguna Kredit. (Kasus: Petani Tebu Anggota Koperasi Madusari, Pabrik Gula Tasikmadu Karanganyar, Solo). Skripsi. IPB, Bogor.
Nurhapsa, 2015. Perilaku Risiko Produktivitas Petani Kentang di Kabupaten Enrekang, Provinsi Sulawesi Selatan. Prosiding Konferensi Nasional XVII dan Kongres XVI Perhimpunan Ekonomi Pertanian (PERHEPI) 